\section{Hochdosis-Interferon ohne Vorteil bei positivem Sentinel}

\begin{abstract}
Die ambitioniert gestartete Studie "Sunbelt Melanoma Trial" zur Interferontherapie von Melanompatienten mit einem positiven Sentinellymphknoten hat keine Vorteile für die immunstimulierende Behandlung erbracht.
\end{abstract}

\begin{abstract}
n die Sunbelt-Melanom-Studie wurden von 1997 bis 2003 insgesamt 774 Patienten mit einem Melanom von mindestens $1 \mathrm{~mm}$ Dicke aufgenommen. Bei allen Studienteilnehmern wurde eine Biopsie der Sentinellymphknoten vorgenommen. War ein einzelner Sentinel positiv, unterzog man die Patienten dem Therapieprotokoll A: komplette Lymphknotendissektion, anschließend entweder beobachtendes Vorgehen oder eine Behandlung mit hochdosiertem Interferon $\alpha-2 b$. War die Sentinelbiopsie histopathologisch und immunhistochemisch negativ, aber in der Reverse-Transkriptase-PolymeraseKettenreaktion (RT-PCR) positiv auf
\end{abstract}

melanomspezifische Messenger-RNA, trat Protokoll B in Kraft: Beobachtung versus komplette Lymphknotendissektion versus komplette Lymphknotendissektion plus Hochdosis-Interferon.

Die Nachbeobachtungszeit betrug median knapp sechs Jahre. Ein Unterschied im krankheitsspezifischen oder im Gesamtüberleben zwischen den einzelnen Therapiearmen war weder unter Protokoll A noch unter Protokoll B festzustellen. Damit ergab sich kein Vorteil für Patienten, die einer hochdosierten Interferongabe ausgesetzt waren. $\mathrm{Zu}$ dem zeigte sich in Protokoll B, dass ein molekulares Staging mit RT-PCR keinen prognostischen Nutzen nach sich zieht. Allenfalls zeigte sich hier ein Vorteil der kompletten Lymphknotendissektion im Vergleich zum abwartenden Beobachten mit Blick auf das krankheitsfreie Überleben. Obwohl signifikant (Hazard Ratio 0,58; $\mathrm{p}=0,028$ ), schlug sich dieser Effekt nicht in einem verbesserten Gesamtüberleben nieder. Die Autoren spekulieren, dass sich hier der Rückgang regionaler Rezidive bemerkbar mache, der aus der Lymphknotendissektion resultiert.

Fazit: Eine Interferontherapie von Melanompatienten mit einem positiven Sentinellymphknoten zeigte keine Überlegenheit im Gesamtüberleben gegenüber Beobachten.

Dr. Robert Bublak

McMasters KM et al. Final Results of the Sunbelt Melanoma Trial: A Multi-Institutional Prospective Randomized Phase III Study Evaluating the Role of Adjuvant High-Dose Interferon Alfa-2b and Completion Lymph Node Dissection for Patients Staged by Sentinel Lymph Node Biopsy. J Clin Oncol 2016; 34: 1079-86

\section{Kleienpilzflechte macht die Haut scheckig}

Eine 24-jährige Frau hatte seit zwölf Jahren eine ausgedehnte, konfluierende Hypopigmentierung an der Außenseite der Oberarme (Abb. A). Die Hautveränderungen waren vor allem im Sommer ausgeprägt und hatten sich zwei oder drei Jahre vor der Untersuchung sogar über den gesamten Oberkörper ausgebreitet. Hinzu kam eine starke Hautschuppung vor allem nach dem Duschen. Die Frau befürchtete nun, dass sich die Effloreszenzen auf das Gesicht ausdehnen könnten. Therapieversuche mit mehreren topisch applizierten Antimykotika hatten nicht zu einer dauerhaften Remission geführt.

Zum Ausschluss einer Vitiligo wurde eine Hautbiopsie durchgeführt. Spezialfärbungen mit Melanin-A zeigten eine normale Verteilung von Melanozyten (Abb. B). Eine PAS-Färbung ließ in der oberflächlichen Epidermis Hefepilze erkennen (Abb. C). Eine Hautschuppung, die in vor allem bei Hautdehnung auftritt, spricht stark für eine Pityriasis versicolor. Für die Diagnosestellung empfiehlt sich die mikroskopische Untersuchung von abgeschabten Schuppen nach Vorbehandlung mit Kaliumhydroxid oder Chlorazol Black E. Angesichts des ausgedehnten Hautbefalls wurde die Patientin oral mit Fluconazol und topisch mit Ketoconazol behandelt. Sie stellte sich nicht zur Verlaufskontrolle vor. Auch nach Beseitigung der Pilze kann der Prozess der Hautrepigmentierung mehrere Monate in Anspruch nehmen.

Prof. Hermann S. FüeßI

Holliday A at al. Tinea versicolor. N Engl J Med 2016; 374: e11
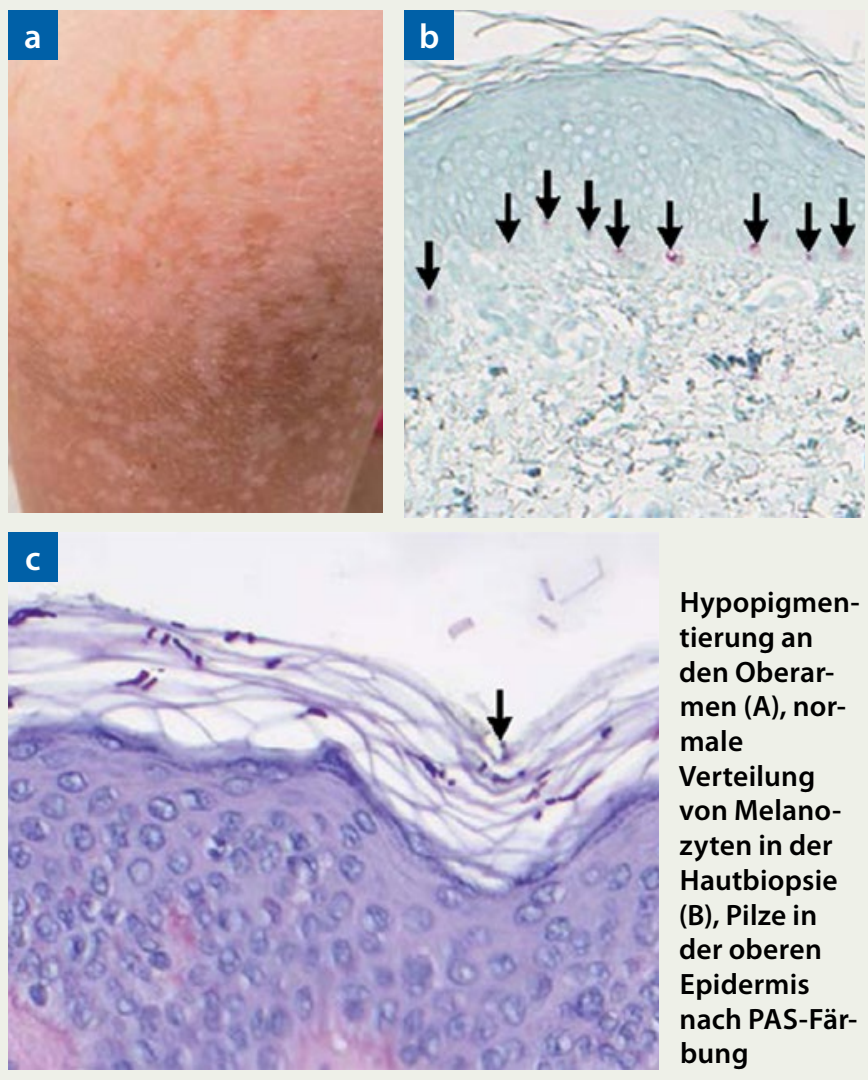

Hypopigmentierung an den Oberarmen $(A)$, normale Verteilung von Melanozyten in der Hautbiopsie (B), Pilze in der oberen Epidermis nach PAS-Färbung 